\title{
Summer Lovin'
}

\section{Pauline Blachford}

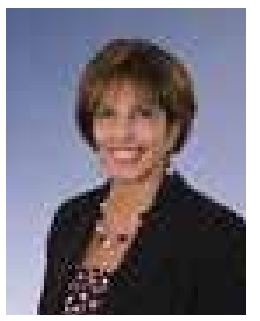

Pauline Blachford consults optometrists on how to reduce unbooked appointments, increase eyewear sales, and improve employee productivity. She has abundant experience in the eye health industry, including 17 years at White Rock Optometry in B.C. Pauline frequently presents at optometry conferences and is a regular columnist for the CJO. For more information, visit paulineblachford.com.

Cummer is a wonderful season for optometrists. It's a time to take that much-needed

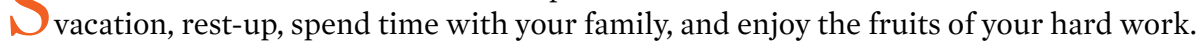

One of the greatest things about owning a practice is that your business can continue to heat up, even while you cool down poolside, icy drink in hand. All it takes is a little bit of foresight and planning. In anticipation of my favourite season, here are four recommendations I give my clients to ensure they maximize their revenue potential and improve their business practices, all while they and their staff take time for fun in the sun.

\section{Strategic Telephone Recalling}

Over two decades in the eye health field, I have found that summer can be one of the busiest times of year. This contradicts the wide-held belief that summer is inherently slow because our clients are on holiday. The key to maximizing bookings during the summer is strategic telephone recalling. If your clinic does not already have a rigorous telephone recalling strategy, read my article, Take Action to Ensure Client Loyalty. ${ }^{1}$

Strategic telephone recalling is when your "recaller" phones clients based on a particular characteristic in each client's profile-not just because the client is the next person on your list who is due for an exam. In preparing for the summer, I coach recallers to target their senior citizen clients when booking appointments for June. This is when young families are busy with exams, class parties, graduations, the works. Things settle down during the summer, and that's when I coach my recallers to reach out to families. It goes something like this:

"Hi Mrs. Smith; it's Suzie from Brooksfield Optometry. I'm calling to book Jimmy and Ashley for their yearly eye health exam. I thought it would be good to book them in July, when they're not busy with school. You're also due for an exam ..."

This type of recalling will keep your practice busy right through the summer. And the children you serve this summer will be the adolescents and adults you service in years to come.

\section{Hire A Locum}

Maximizing your revenue means maintaining momentum and continuing to operate your business, even when you are on vacation. Doing this requires having an optometrist on staff to carry your workload forward. Hiring a locum generates revenue in the short term, while providing the long-term benefits that come from offering your clients the continuous care they deserve. $^{2}$ 
I always tell my clients that if it takes more than five to seven days for your patients-especially your new patients-to get an appointment, then you're doing a favour to the optometrist down the street. Our CAO president, Dr. Geneau, has worked as a locum and hired locums himself. He says he only hires locums he is sure will provide high-quality service to his patients. He asks optometrists he went to school with to fill in for him or to recommend someone trustworthy. ${ }^{3}$

\section{Cross-Train Your Staff}

Having a cross-trained staff brings big benefits to your business all year round. Research shows that when each of your employees knows the roles, responsibilities, and duties of her colleagues, it helps to provide quality control, pleases patients, promotes teamwork, generates greater employee buy-in, and boosts morale. ${ }^{4}$ If you still expect your practice will slow down come summer, use this extra time to cross-train your staff. This will give you experienced substitutes when employees take vacation. It will also serve the practice when an employee falls ill or takes parental leave. Cross-trained staff provides affordable options for mitigating the impact of labour shortages. ${ }^{5}$

Implementing an effective cross-training program, however, requires a plan. ${ }^{6}$ Start by having your staff identify the skills they hold as a team. This talent inventory will highlight team strengths and hidden skills, while illuminating areas where a staff shortage could result in operational challenges. From there, establish job-training sessions that focus on the areas where your practice could grow or improve. These can range from hiring a skilled expert to coach certain members of your team to having your employees take turns shadowing one another.

\section{Catch-Up and Improve}

If your practice does experience some downtime in the summer, another way to stay productive is by completing the chores that have piled-up over the year ${ }^{[3]}$. Begin by asking your staff to compile a list. Start now, while your practice is busy; that's when uncompleted chores and inefficiencies are most glaring. Items on the list may include catching up on telephone recalling; updating your website; calling patients who have not picked up their contact lenses; sorting and re-ordering contact lens samples; purging your inventory of expired products; shipping back returned items; cleaning; scanning paper files into your computer system, or catching up on other filing. ${ }^{7}$

Leading up to the summer, have each employee sign up to complete one or two of the chores on the list. To motivate your staff, talk to them about how much better it will be once these tasks are complete. Have them decide how the team will celebrate at the end of the summer, if everyone completes their chores.

Summer brings just as many opportunities for your practice to shine as it does occasions for great holidays. Vacation time and staff shortages don't have to burn your bottom line. Strategic telephone recalling and a trusted locum can make this summer your most profitable yet. And if your business does see some downtime, make productive and profitable use of it to enhance your employees' skill sets, and knock off piled-up chores so your practice can hit the ground running in the fall.

\section{REFERENCES}

1. Blachford P. Take Action to Ensure Client Loyalty. CJO 2013;75(4):14. http:/gpintegrated.ca/CJORCOv75n5/ CJORCOv75n5.html\#p=16 2 Lowes, R. Locum tenens: when you need one, how to get one. Medical Economics 2007: 33-45.

2. Lowes R. "Locum tenens: when you need one, how to get one", Medical Economics, vol. 84, nº 9 (May 2007), p. 33-45.

3. Here are some other suggestions for hiring a locum: Clarke, P. Locum finding tips 2002;38(38): 37,39.

4. The benefits of cross-training staff. Medical Economics 2005: 42-45.
5. Hertzfeld, E. Cross-training: Expanded roles help staff serve guests better. Hotel Management. 38-39.

6. Reference for Business. In Encyclopedia of Business, 2nd Ed. Retrieved from http://www.referenceforbusiness.com/small/Co-Di/Cross-Training.html.

7. Dealing with seasonal changes in workload. [Mind Tools website]. Available at: www.mindtools.com/ pages/article/seasonal-workload-changes.htm. Accessed February 23, 2015.

8. Smith J. "10 things to do on a slow day at work." [Forbes website]. Available at: http://www.forbes.com/sites/ jacquelynsmith/2013/01/09/10-things-to-do-on-aslow-day-at-work. Accessed: February 23, 2015 